\title{
The Influence of Passion/Determination and External Disadvantage on Consumers' Responses to Brand Biographies
}

Thanh-Thao Nguyen and Bianca Grohmann

To cite this article: Nguyen, Thanh-Thao and Bianca Grohmann (2020), "The Influence of

Passion/Determination and External Disadvantage on Consumers' Responses to Brand Biographies," Journal of Brand Management, 27, 452 - 465. doi: 10.1057/s41262-020-00193-8

To link to this article: https://doi.org/10.1057/s41262-020-00193-8 
The Influence of Passion/Determination and External Disadvantage on Consumer Responses to Brand Biographies

\begin{abstract}
Brands frequently convey their stories in brand biographies in order to elicit positive consumer responses. This article examines the influence of consumers' perceptions of passion/determination and external disadvantage reflected in brand biographies on narrative transportation, consumers' post-message engagement, and purchase intentions. Results suggest that passion/determination affects purchase intentions positively, both directly and through narrative transportation and post-message engagement. External disadvantage, on the other hand, affects purchase intentions positively and indirectly through narrative transportation and postmessage engagement, while there is no significant direct effect. This article specifically considers the individual roles of passion/determination and external disadvantage in influencing consumer responses to a brand. It is also the first to consider and empirically test the role of postmessage engagement in consumers' responses to brand biographies. This research has implications for theory, as well as for the creation of effective brand biographies in managerial practice.
\end{abstract}

Keywords: Brand biographies; narrative transportation; post-message engagement. 


\section{Introduction}

"The Google story begins in 1995 at Stanford University. Larry Page was considering Stanford for grad school and Sergey Brin, a student there, was assigned to show him around. By some accounts, they disagreed about nearly everything during that first meeting, but by the following year they struck a partnership. Working from their dorm rooms, they built a search engine that used links to determine the importance of individual pages on the World Wide Web. They called this search engine Backrub.

Soon after, Backrub was renamed Google (phew). The name was a play on the mathematical expression for the number 1 followed by 100 zeros and aptly reflected Larry and Sergey's mission "to organize the world's information and make it universally accessible and useful." (www.google.com/about/our-story)

Many of the world's most recognized brands — such as Google, Apple, or Airbnb — are based on humble, and sometimes challenging, beginnings that their enthusiastic founders were able to overcome with passion and determination. In Google's case, a partnership of two students who found themselves working from their dorm rooms turned into a success story due to the founders' determination to turn their ambitious mission into reality. Brand biographies are narratives tracing the beginnings and growth of the brand and are often an important part of brand websites or secondary accounts of the brand trajectory to market leadership (Paharia et al, 2011).

The increasingly widespread use of brand biographies indicates that they are seen as important component of brand communication and persuasion strategies. Research indeed suggests that brands associated with biographies that reflect brands' initial challenge in overcoming limited resources and disadvantaged origins with passion and determination evoke positive consumer responses, such as brand preferences (Paharia et al, 2011). Brand biographies that provide an account of initial disadvantages and a brand's passion and determination in overcoming them are referred to as underdog brand biographies (Paharia et al, 2011). Consumers perceive brand with underdog brand biographies especially favorably when they share the 
underdog identification with the brand (Keinan et al, 2010; Kao, 2015; Paharia et al, 2011), live in a context in which underdog narratives are part of cultural identity (Paharia et al, 2011), or purchase products for themselves (Paharia et al, 2011). In addition, consumers' support for underdog brands increases when these brands are in direct competition with larger competitors (Paharia et al, 2014).

Exposing consumers to a brand biography reflecting passion/determination and external disadvantage is an important part of the persuasive process leading up to greater preferences and purchase intentions of consumers. As consumers read brand biographies, they may lose themselves in the story (Van Laer et al, 2014), such that cognitive resources become focused on the events occurring in the narrative (Green and Brock, 2000). When this is the case, narrative transportation occurs, such that consumers are transported into the narrative world (Green and Brock, 2000). Because of narrative transportation, people may experience the emotions reflected in the story, and are more likely to accept the narrative world which was created by authors and engage in narrative-consistent attitude change (Green and Brock, 2000; Green et al, 2008). Importantly, consumers are influenced by narratives not only at the time of reading, but also after the narrative's ending. Emotional responses evoked by the narrative may lead to increased postmessage engagement (Nabi and Green, 2015). Post-message engagement consists of consumers' information seeking, repeated exposure, higher levels of elaboration on the narrative, social sharing, and memory in response to a message (Nabi and Green, 2015). The literature suggests that post-message engagement increases a narrative's persuasive power (Nabi and Green, 2015). This could have positive implications for a brand that is featured in a narrative.

In sum, the literature demonstrates a positive effect of brand biographies that convey a great extent of passion/determination and external disadvantage on narrative transportation (Van 
Laer et al, 2014), and brand preferences and purchase intentions (Avery et al, 2010, Paharia et $a l, 2011,2014)$. More recent conceptual developments also suggest that post-message engagement is implicated in the persuasion process triggered by narratives (Nabi and Green, 2015).

The goal of the current research is to shed light on the processes underlying the effect of passion/determination and external disadvantage conveyed in brand biographies by integrating both narrative transportation and post-message engagement in a conceptual model of the impact of brand biographies on consumer responses to the brand. Although research has revealed positive outcomes in response to brand biographies, the underlying mechanisms have received less attention. This article seeks to contribute to the brand biography literature in two ways: First, it aims to replicate the positive effect of passion/determination and external disadvantage that are conveyed in brand biographies on consumers' purchase intentions, but examines the individual contribution of passion/determination and external disadvantage conveyed in a brand biography on consumers' purchase intentions and the processes leading up to them. Past research has relied on experimental manipulations of underdog and topdog brand biographies (Paharia et al, 2011), whereas the current research measures perceived passion/determination and external disadvantage, and examines their independent influence on consumer responses.

Second, this research sheds light on whether and to what extent narrative transportation and consumers' post-message engagement mediate the effects of passion/determination and external disadvantage reflected in brand biographies on purchase intentions. While the literature has begun to acknowledge the role of narrative transportation in the context of brand biographies (Van Laer et al, 2014), the consideration of consumers' post-message engagement with the brand as a mediator leading up to purchase intentions is novel. In addition to these theoretical 
contributions, this article seeks to inform managerial practice with regard to the use of information regarding a brand's passion/determination and external disadvantage in the creation of effective brand biographies.

This article is organized as follows: First, it develops a conceptual framework building on the brand narrative, brand biography, narrative transportation, and post-message engagement literature. The predictions regarding the impact of passion/determination and external disadvantage on consumers' purchase intentions, and the mediating roles of narrative transportation and consumers' post-message engagement are then empirically tested in a study involving adult consumers. The article concludes with a discussion of the theoretical and managerial implications of the findings, the limitations of this research, and future research directions.

\section{Theoretical background}

\section{Brand Narratives}

Stories are a means of communication that helps people relate the content of the story to their own experiences and store new information in memory (Cooper et al, 2010; Escalas, 2004; Woodside et al, 2010). Narratives are structured around a coherent theme, imply a temporal sequence of events, and convey actions of focal characters (Adaval and Wyer, 1998; Escalas, 2004). Because a narrative structure mirrors life experiences, the information presented in narrative form is easy to understand, is associated with high levels of credibility, facilitates affective responses, and is easily incorporated into people's judgment (Adaval and Wyer, 1998). In communicating with consumers, brands widely engage in storytelling by means of 
advertising (Escalas, 2004; Twitchell, 2004), product placement in movies (Cooper et al, 2010), as well as in conveying the brand's developmental trajectory in trade publications, books, or on brand web sites (Paharia et al, 2011). Narratives involving the brand are so powerful that brands have been characterized as "a story attached to a manufactured object" (Twitchell, 2004, p. 484). Narratives are an effective means of brand communication because they elicit emotions (Adaval and Wyer, 1998; Twitchell, 2004) and help consumers relate brand information to their own experiences (Cooper et al, 2010; Escalas, 2004). The literature indeed points toward a positive impact of narratives on consumer responses: Compared to lists, narratives evoke a greater extent of affective reactions, and more positive consumer evaluations (Adaval and Wyer, 1998). In the context of advertising, narratives also resulted in greater self-brand connections, and subsequent brand attitudes and purchase intentions (Escalas, 2004). From a consumer perspective, the narrative associated with brands not only affects consumer's affective, evaluative, and behavioral responses to brands, but also allows consumers to extract the meaning created through brand storytelling by acquiring and consuming brands to create their own life narrative (Schembri et al, 2008; Woodside et al, 2008).

\section{Brand Heritage}

The use of storytelling allows brands to develop their own histories (Hatch and Rubin, 2006). The history of a brand that is conveyed in brand narratives gives rise to consumer perceptions of brand heritage (Pecot et al, 2018). Brand heritage is defined as "a dimension of a brand's identity found in its track record, longevity, core values, use of symbols and particularly the organizational belief that history is important" (Urde et al, 2007, p. 4). Brand heritage reflects a brand position that emphasizes a brand's history and links it to the brand's current circumstances (Rose et al, 2016; Urde et al, 2007), and is conceptualized as a brand's link to the past (Pecot et 
al, 2018). Importantly, brand heritage is rooted in consumers' perception of a brand' history rather than fact and is thus influenced through the effective use of brand communications (Pecot et al, 2018). Brand heritage is an important driver of consumers perceptions of brand image, brand trust, consumer satisfaction, willingness to pay a price premium, and buying intention (Wiedmann et al, 2011). Further empirical findings support a positive influence of brand heritage on brand attachment (Merchant and Rose, 2013) and purchase intentions (Rose et al, 2016). A more recent investigation reports a positive and significant influence of brand heritage on brand credibility, quality, and consistency, as well as subsequent willingness to pay (Pecot et al, 2018).

Overall, its positive effects on consumer responses to the brand make brand heritage a desirable and beneficial outcome that can be achieved by brand storytelling that relates specifically to a brand's past and its subsequent trajectory over time. This type of narrative is the focus of the brand biography literature.

\section{Brand Biographies}

The telling stories in the form of brand biographies is an effective approach to brand communication and positioning, because "narratives help people interpret the world around them to create meaning, including meaning for brands" (Escalas, 2004, p. 169; Woodside et al, 2008). Brand biographies narrate the brand's trajectory over time, and often begin with the founding of the brand. Brand biographies thus evoke the brand's past and often tell stories of brand creators overcoming challenges and disadvantages with passion and determination in order to launch the brand and keep it alive (Paharia et al, 2011). In linking the brand's challenging past to current success, brand biographies have the potential to evoke brand heritage.

Brand biographies that narrate the story of brands that face great external disadvantages 
and, at the same time, also demonstrated high levels of passion and determination with regard to overcoming these challenges, are considered underdog brand biographies (Paharia et al, 2011). In this context, external disadvantages refer to limited financial or economic resources, as well as minority status, whereas passion and determination relate to the brand or brand founder's passion regarding goals, fighting spirit, or strong faith and hope (Paharia et al, 2011). In contrast to underdog brands, top-dog brands are backed by well established companies, are well endowed with resources, and are favored to win in the competition (Paharia et al, 2011). Because of the many disadvantages underdog brands have or had to cope with, they might be expected to lose in the competition against top-dog competitors. From a consumer perspective, underdog brands may be more appealing than top-dog brands, however. An externally disadvantaged brand that demonstrates passion/determination and ultimately thrives against the odds, has the potential to captivate consumers' emotions and imagination. In telling their stories, brands establish connections to consumers' life narratives which describe their self-identity (Shembri et al, 2010). As brands connect to consumers' sense of self, they become more important and valuable to consumers (Escalas, 2004; Escalas and Bettman, 2005). At the same time, brand biographies make the brand appear more alive, providing it with tangibility and believability that makes it easier for consumer to identify with the brand (Avery et al, 2010). Since consumers often include products and brands in reporting their own lived experiences (Shembri et al, 2010; Wallendorf and Arnould, 1988; Woodside et al, 2008), they give preference to a brand if they share aspects of their own lives with the brand. In other words, consumers construct their self-identity through brand choices (Escalas and Bettman, 2005). As a result of greater self-brand connections that arise from brand biographies that resonate with consumers, consumers show greater brand preference and purchase intentions for a brand that is associated with high level of 
passion/determination and external disadvantage (Paharia et al, 2011).

Underdog narratives are prevalent in the North American culture and the focus of literature and popular movies. In addition, North American consumers tend to self-identify as underdogs (Paharia et al, 2011). As a result, North American consumers tend to identify with underdog brand biographies and the brands they refer to, and relate to their struggle (Paharia et $a l, 2011)$. This enhances consumers' brand preference for underdog (vs. topdog) brands. A high level of identification with brands associated with an underdog brand biography also manifests in a greater likelihood of purchasing an underdog brand when buying for oneself versus others (Paharia et al. 2011), presumably because brand-self-identification is high. In sum, the positive effect of underdog brand biographies is moderated by consumers' underdog self-identity, culture, and the purchasing situation (Paharia et al, 2011). For instance, consumers tend to prefer brands associated with an underdog brand biography when purchasing for themselves as opposed to (Paharia et al, 2011).

The positive effects arising for brands associated with a brand biography that conveys high levels of passion/determination and external disadvantage has the potential to overcome negative attributions associated with company size or market power. This occurs because consumers are more likely to identify with the brand's passion and struggles rather than the company's size (Avery et al, 2010). Relatedly, consumers are more likely to identify with large companies when they are associated with an underdog biography, and are happier when thinking about the successes of large companies that come from underdog roots (Avery et al, 2010). Furthermore, the impact of passion/determination and external disadvantage is contingent upon consumers' perception of the competitive context in which the brand operates: Highlighting competition in the context of a salient competitive battle helps an underdog brand increase 
purchase intention and frequency (Paharia et al, 2014). Communication strategies that focus on the competition between underdog brands and prominent competitors increases the support for underdog brands, and decrease the support for topdog brands (i.e., topdog brands; Paharia et al, 2014). Not only do consumers support underdog brands to a greater extent when competition is emphasized, they also tend to punish larger brands (Paharia et al, 2014).

The first objective of the current research is to replicate and extend prior studies regarding brand biography effects, by examining the individual contribution of passion/determination and external disadvantage reflected in brand biographies. Previous research used experimental manipulations to categorize brand as underdog or topdog to examine the impact of biography type (Paharia et al, 2011). Underdog brands are characterized by high passion/determination and high external disadvantage, whereas topdog brands are characterized by low passion/determination and low external disadvantage (Paharia et al, 2011).

In focusing on the passion/determination and external disadvantage aspects individually, this current research not only seeks to replicate positive effects of these two aspects of brand biographies, but also aims at exploring their relative weight, as well as the subsequent processes by which they influence consumers' purchase intentions. Based on the consistent findings in the underdog brand biography literature (Paharia et al, 2011), we expect a positive influence of the level of passion/determination and a positive influence of external disadvantage reflected in a brand biography on consumers' purchase intentions.

H1a: Passion/determination conveyed by a brand biography positively and significantly relates to consumers' purchase intentions.

H1b: The degree of external disadvantage conveyed in a brand biography positively and significantly relates to consumers' purchase intentions. 


\section{Narrative Transportation}

Narrative transportation is a state of immersion. It is defined as the extent to which an individual becomes "lost" in a story (Green and Brock, 2000). Narrative transportation is an experiential response to narratives (Prentice and Gerrig, 1999) that consists of attention, imagery, and emotion focused on events occurring in the story (Green and Brock, 2000; Gerrig, 1993). Narrative transportation requires the creation of a narrative world that evokes characters and settings, rather than merely emotions (Green and Brock, 2000; Green et al, 2004). Once such a narrative world is created, transportation occurs when attention is focused on events conveyed in the narrative (Gerrig, 1993; Green and Brock, 2000). Depending on the narrative's text quality, reading goals, readers' susceptibility to narrative transportation (Dal Cin et al, 2004; Green, 1996; Mazzocco et al, 2010), and prior relevant knowledge (Green, 2004), the focus on the events in a narrative may be so intense that people are no longer aware of their environment (Green and Brock, 2000). Narrative transportation also involves strong imagery so that the events in the narrative appear plausible and real, and the emergence of emotions in responses to the events reflected in the narrative (Green and Brock, 2000).

Higher levels of narrative transportation result in a greater likelihood of story-consistent attitude formation or change (Green and Brock, 2000). For example, more (vs. less) transported readers are more likely to believe that a mall is a dangerous place after reading a narrative about an attack at a shopping mall (Green and Brock, 2000). These attitude and belief changes in response to narratives tend to be based on emotional rather than rational responses (Mazzocco et al, 2010; Slater and Rouner, 2002). In fact, transportation may lead to persuasion by reducing negative cognitive responding, increasing the realism of the experience, and through emotional 
responses (Green and Brock, 2000): First, narrative transportation may decrease the negative cognitive elaboration on the story content as transported individuals are less likely to disbelieve claims made in the narrative (Green and Brock, 2000). Second, narrative transportation increases the realism and plausibility of events and may therefore increase the perceived veracity of claims made in the narrative (Green and Brock, 2000). Finally, narrative transportation associated with the development of emotional responses about the events and characters described in the narrative (Green and Brock, 2000; Green et al, 2004). As a result, readers' processing of the narrative is emotional rather than analytic and may thus result in persuasion even in the absence of strong persuasive arguments (Escalas, 2007).

In sum, the literature suggests that narrative transportation is an important mediator in the persuasion process linking narratives to attitude change (Green and Brock, 2000). In the context of brand biographies, narrative transportation is thus likely to mediate the relation between the narrative content of the brand biography, and consumer responses to the brand.

\section{Post-Message Engagement}

Emotion is a fundamental part of the narrative experience (Nabi and Green, 2015; Oatley, 1999), and mediates the persuasive effects of narratives (Mazzocco et al, 2010). Narratives elicit a series of emotional shifts in the reader. This is particularly the case for narratives that trace the protagonist's overcoming of challenges and obstacles (Nabi and Green, 2015). The emotions evoked by the narrative are an important part of the narrative transportation readers experience while reading the story (Green and Brock, 2000). In addition, narrative-based emotions may have effects that extend beyond the end of the narrative (Nabi and Green, 2015). The emotions elicited by a narrative may motivate readers to engage with the narrative to a greater extent, and 
therefore result in a number of post-message engagement behaviors that subsequently enhance the narrative's persuasive potential. As such, "emotions are not simply a featured element of narratives, but they are strongly implicated in the process of how narratives generate persuasive outcomes" (Nabi and Green, 2015, p. 143).

A recent conceptual treatment of the role of post-message engagement (Nabi and Green, 2015) proposes that the emotions evoked in the narrative transportation process lead to several post-message engagement processes that subsequently elicit attitude and belief change. These post-message engagement processes include repeated exposure, information seeking, postmessage elaboration, social sharing, and memory (Nabi and Green, 2015). Repeated exposure is motivated by readers' wish to re-experience the emotions triggered by a narrative, and involves rereading or reviewing a narrative (Nabi and Green, 2015). In a brand context, repeated exposure could consist of repeated watching of narrative ads (e.g., Super Bowl ads), or rereading of brand biographies on websites. Post-message engagement may also take the form of information seeking (Nabi and Green, 2015). In seeking more information, readers look either for a continuation of or possible resolution to the narrative; they may also search for more information regarding the narrative's topic. Information seeking helps readers relieve anxiety or other emotions triggered by the narrative, and addresses curiosity that was induced by the narrative (Nabi and Green, 2015). Information seeking is a form of post-message engagement that could be of particular interest to brands, because it may motivate consumers to visit brand websites or stores to find out more about brand attributes. Both repeated exposure and information seeking require that consumers reengage with the message. Nabi and Green (2015) propose that the involvement necessary to incite reengagement is more likely to occur for narratives that are engaging, arousing, and generate a high level of narrative transportation. Brand biographies that 
highlight struggles, passion, and determination should therefore induce higher levels of narrative transportation and, in turn, post-message brand engagement. In other words, higher levels of narrative transportation relate positively to repeated exposure and information seeking.

A third type of post-narrative engagement consist of post-narrative message elaboration (Nabi and Green, 2015). Narratives that evoke emotions in the reader or do not present a full resolution motivate more extended narrative elaboration (Nabi and Green, 2015). This means that readers invest cognitive resources to make sense of the emotional trajectory or the ending of the narrative. This results in a higher level of involvement with the narrative and additional elaboration is likely to readers' perceptions in a message-consistent way (Petty and Cacioppo, 1986). This elaboration relates to the narrative and the emotions it evoked rather than on the strength of arguments presented in the story (Nabi and Green, 2015). Increased levels of postmessage elaboration and subsequent message-consistent reactions occur for narratives that generate a higher level of narrative transportation (Nabi and Green, 2015).

A fourth form of post-message engagement consists of readers' memory for the content of the narrative. Memory is influenced by the level of arousal a narrative evokes, as well as the level of post-message elaboration (Nabi and Green, 2015). Narratives that relate emotionally arousing stories attract attention and help build memory (Cahill and McGaugh, 1995). In addition, higher levels of post-message elaboration associated with emotional narratives (Nabi and Green, 2015) also strengthens memory. Finally, post-message engagement also encompasses social sharing of emotions and information regarding the narrative (Nabi and Green, 2015). The extent of social sharing is positively associated with the degree of the reader's emotional experience (Nabi and Green, 2015; Rimé, 1995), as sharing helps people to make sense of their emotions, validate themselves, but also to connect to others (Nabi and Green, 
2015). In a brand context, social sharing could involve discussing brand narratives with others, reposting brand messages on social media, or posting one's own reaction to brand narratives on social media. It could also involve the sharing of experiences involving the brand with others. Narratives that are high in emotionality are expected to result in higher levels of social sharing (Nabi and Green, 2015). As emotionality undergirds both narrative transportation and social sharing, a positive relation between narrative transportation and social sharing is likely.

Overall, a narrative that leads to high levels of transportation is expected to lead to higher levels of post-message engagement in the form of repeated exposure, information seeking, and post-message elaboration, memory, and social sharing. This link has been suggested in prior literature (Nabi and Green, 2015), but has not been empirically examined.

The brand biography - narrative transportation - post-message engagement link

The current research moves the conceptualization of the narrative-narrative transportation-post-message engagement-response link into a brand biography context. In the domain of brand biographies the notion of narrative transportation plays an important role in the persuasive effect of brand biography that convey passion/determination and external disadvantage (Van Laer et al, 2014). The narrative transportation literature suggests that narratives have the power to change attitudes, beliefs and behaviors of the recipients of narrative information (Escalas, 2004; Green, 2004; Green and Brock, 2000; Hormes et al, 2013); transported individuals show more story-consistent beliefs and opinions than their less transported counterparts (Mazzocco et al, 2010). Moreover, recent research suggests a sequential mediation of narrative effects on persuasion through narrative transportation and post-message engagement (Nabi and Green, 2015). Combining these research streams, the current research 
examines the following sequential mediation hypotheses for the influence of passion/determination and external disadvantage on consumers' purchase intentions:

H2a: Increased purchase intention for brands with a biography that expresses higher levels of passion/determination will be mediated by narrative transportation and consumers' post-message engagement.

$\mathrm{H} 2 \mathrm{~b}$ : Increased purchase intention for brands with a biography that expresses higher levels of external disadvantage will be mediated by narrative transportation and consumers' post-message engagement.

As illustrated in the conceptual framework shown in Figure 1, this research tests the influence of the passion/determination and external disadvantage dimensions of an underdog brand biography on narrative transportation and consumers' post-message engagement with the brand, and ultimately brand purchase intention.

Insert Figure 1 about here

\section{Method}

\section{Pretest}

This research focuses on the effect of written brand biographies on consumers' narrative transportation, post-message engagement, and subsequent purchase intentions. To examine the effects across a range of passion/determination and external disadvantage levels reflected in brand biographies, this research employed two brand biographies to generate variance for the 
predictor variables. These biographies followed the structure and content of brand biographies used in earlier academic research (study 4; Paharia et al, 2011). It comprised an underdog brand biography reflecting high levels of passion/determination and external disadvantage, and a topdog brand biography reflecting low levels of passion/determination and external disadvantage. The brand biographies were adapted to the orange juice product category to extend prior research. The fictitious brand name Juicy Juice was applied to both the underdog and the topdog brand biography. A fictitious brand was used to rule out potential effects of consumer knowledge and experience on consumer responses measured in this research. The goals of the pretest were to verify consumer perceptions of the passion/determination and external disadvantage reflected in the two brand biographies, and to examine the correlation between these two dimensions of consumer responses to brand biographies (Paharia et al, 2011). This was important in order to determine whether a consideration of passion/determination and external disadvantage as independent predictors of consumer responses to brand biographies was appropriate. Moreover, the pretest served to verify that brand biographies did not influence consumers' quality perceptions, brand familiarity, and brand attitude.

Eighty-one adult North American consumers (50.6\% female, 18-74 years old) recruited through an online consumer panel were randomly assigned to one of two brand biography conditions (topdog biography: $n=40$; underdog biography: $n=41$ ). After reading the brand biography, participants completed measures of passion/determination and external disadvantage: "How passionate and determined is this brand?" and "How externally disadvantaged is this brand?" anchored not at all/very much (Paharia et al, 2011). They also reported brand attitude (seven items, e.g., good/bad, positive/negative; Priester et al, 2004), quality perceptions (poor/excellent overall quality, very poor/good quality, poor/excellent; Sprott and Shimp, 2004), 
and brand familiarity (not at all/extremely familiar, definitely do not recognize/definitely recognize, definitely have not heard of it before/definitely have heard of it before; Simonin and Ruth, 1998). All scales used in the pretest and main study were selected based on their validation and use in prior brand biography or branding literature. All scales were measured on seven points. The questionnaire concluded with demographic questions.

The measures of passion/determination and external disadvantage did not correlate significantly $(r(81)=.13, p=.25)$. This suggests that it is appropriate to examine their independent influence on consumer responses to brand biographies. Passion/determination and external disadvantage differed significantly across the two brand biographies, such that the underdog brand biography was associated with more passion/determination $\left(\right.$ Mean $_{\text {Underdog }}=5.98$, $\left.\operatorname{Mean}_{\text {Topdog }}=5.18, t(81)=2.51, p=.01\right)$ and external disadvantage $\left(\operatorname{Mean}_{\text {Underdog }}=4.56, \mathrm{Mean}_{\text {Topdog }}\right.$ $=2.88, t(81)=4.35, p=.000)$.

Following a factor analysis, the brand attitude, quality, and brand familiarity items were averaged into an attitude $(\alpha=.95)$, quality ( $\alpha=.96)$, and familiarity $(\alpha=.96)$ index, respectively. There were no significant differences across brand biographies with regard to brand familiarity $(p=.86)$ and quality perceptions $(p=.26)$. However, there was a significant difference with regard to brand attitude $\left(\mathrm{Mean}_{\text {Underdog }}=5.36, \mathrm{Mean}_{\mathrm{Topdog}}=4.73, t(81)=2.23, p=.03\right)$. These findings are consistent with prior findings of more positive evaluations for brand associated with an underdog biography (Paharia et al, 2011). Overall, the pretest suggested that the two fictitious brand biographies brands were appropriate for subsequent hypothesis tests.

\section{Main Study}

This study examined the effect of passion/determination and external disadvantage reflected in 
brand biographies on consumers' purchase intentions. It also tested the mediating roles of narrative transportation (Green and Brock, 2010) and post-message engagement (Nabi and Green, 2015).

A sample of 380 adult North American consumers (47\% female, 18 - 84 years old) was recruited through an online consumer panel. Participants were randomly assigned to one of two brand biography conditions (topdog biography: $\mathrm{n}=184$; underdog biography: $\mathrm{n}=196$ ). After reading the brand biography, participants rated the perceived level of the brand's external disadvantage and passion/determination on the items "How passionate and determined is this brand?" and "How externally disadvantaged is this brand?" anchored not at all/very much; (Paharia et al, 2011). Next, participants completed the narrative transportation scale (twelve items, e.g., "I was mentally involved in the narrative while reading it." Green and Brock, 2000), the post-message engagement scales measuring information seeking (two items, e.g., "How likely would you be to search for more information about the brand?" anchored not likely/very likely; based on Nabi and Green, 2015), post-narrative message elaboration (four items, e.g., "Did you think deeply about the information contained in this message?" anchored very little/a lot; Wheeler et al, 2005), and social sharing ("How likely would you be to share this brand with other people?" anchored not likely/very likely; based on Nabi and Green, 2015). Because the cross-sectional study design required the measurement of consumer processes and responses at one point in time, consumers' brand memory and voluntary revisiting of the brand biography could not be evaluated as these measures require a longitudinal study design. Measures of brand interest (three items, e.g., "How loyal would you be to this brand?" anchored not at all loyal/very loyal; Paharia et al, 2011) and purchase intention (four items, e.g., "How likely would you be to purchase a product made by this brand?" anchored not likely/very likely; Paharia et al, 2011) 
captured consumer responses to brand narratives. All scales were established measures used in the brand biography, narrative transportation, and post-message engagement literature, and measured on seven points. The questionnaire concluded with demographic questions.

\section{Results}

\section{Factor analyses}

The purchase intention and brand interest scales loaded on one factor and had high corrected item-total correlations $(>.50)$. They were therefore averaged into a purchase intention index $(\alpha=$ .94). Factor and reliability analyses indicated that the three reverse scored items of the twelveitem narrative transportation scale (Green and Brock, 2000) loaded on a separate factor and were associated with low corrected item-to-total correlation values $(<.50)$. The three reverse scored items were therefore removed, and the remaining items collapsed into a narrative transportation index $(\alpha=.89)$. Finally, based on a factor analysis revealing one factor and high corrected itemto-total correlations $(>.50)$, the two information seeking items, the four elaboration items, and the social sharing item were collapsed into a post-message engagement index $(\alpha=.88)$.

\section{Regression analysis}

Passion/determination did not correlate significantly with external disadvantage expressed in the brand biographies $(r(380)=.09, p=.07)$. To examine to what extent the two dimensions of an underdog biography (i.e., passion/determination, external disadvantage) independently and directly affect consumers' purchase intention, a regression was performed. The overall model was significant $(F(2,379)=58.67, p=.000)$, as was the coefficient for passion/determination $(b$ 
$=.51, p=.000)$. The coefficient for external disadvantage did not reach significance $(b=.05, p=$ .141). These results indicate a significant and positive direct effect of passion/determination on consumers' purchase intention, supporting hypothesis H1a. The results failed to support hypothesis $\mathrm{H} 1 \mathrm{~b}$, as there was no significant direct effect of external disadvantage on consumers' purchase intention.

\section{Mediation analyses}

The hypotheses suggest that the relation between passion/determination and external disadvantage is mediated by narrative transportation and post-message engagement. The total, direct and indirect effects in a model with two serial mediators was tested in a PROCESS model (Hayes, 2013). Because PROCESS models only allow for the test of one predictor in the context of two serial mediators, the analyses regarding the impact of passion/determination and external disadvantage were conducted individually.

A PROCESS model (model 6 with 5,000 samples; Hayes, 2013) with passion/determination serving as predictor, narrative transportation and post-message engagement as mediators, and purchase intention as the criterion, showed a significant and positive direct effect $\left(\right.$ effect $_{c^{\prime}}=.24,95 \%$ CI $\left.[.17 ; .30], t=6.90, p<.000\right)$ as well as a positive and significant total effect (effect $c_{c}=.51,95 \%$ CI $\left.[.42 ; .61], t=10.72, p<.000\right)$ of passion/determination on purchase intention. The indirect effects through narrative transportation $($ effect $=.05,95 \%$ CI $[.03 ; .09])$, post-message engagement $($ effect $=.14,95 \%$ CI $[.09 ; .19])$, and the narrative transportation-post-message engagement path (effect $=.09,95 \% \mathrm{CI}[.05 ; .13])$ were positive and significant. The strongest indirect effect path was that of passion/determination post-message engagement - purchase intention $($ effect $=.14$ of the sum total indirect effects $=$ 
.28). This suggests that post-purchase engagement plays an important role in mediating the effect of passion/determination.

Overall, the results show significant positive direct effect, total, and indirect effects through two mediators (narrative transportation and post-message engagement) of passion/determination on consumers' purchase intention, as the confidence intervals did not include zero. These findings support hypothesis H2a. The path coefficients, direct (c'), and total effects (c) are displayed in Figure 2.

Insert Figure 2 about here

In a PROCESS model (model 6 with 5,000 samples; Hayes, 2013) with external disadvantage serving as predictor, narrative transportation and post-message engagement as mediators, and purchase intention as the criterion, the direct effect of external disadvantage was not significant $\left(\right.$ effect $\left._{\mathcal{C}^{\prime}}=-.02,95 \% \mathrm{CI}[-.07 ; .03], t=-.72, p=.47\right)$. Nonetheless, there was a positive and significant total effect (effect $\left.t_{c}=.08,95 \% \mathrm{CI}[.008 ; .16], t=2.18, p=.03\right)$ of external disadvantage on purchase intention, as the indirect effects through narrative transportation (effect $=.02,95 \% \mathrm{CI}[.004 ; .04])$, post-message engagement $($ effect $=.04,95 \% \mathrm{CI}$ $[.0009 ; .07])$, and the narrative transportation-post-message engagement path $($ effect $=.04,95 \%$ CI $[.007 ; .08])$ were positive and significant.

Although external disadvantage did not have a significant direct effect on purchase intention, it influenced purchase intention indirectly, and more strongly so through the indirect effect path of external disadvantage - post-message engagement - purchase intention (indirect effect $=.04)$, and the indirect effect path of external disadvantage - narrative transportation - 
post-message behaviors - purchase intention (indirect effect $=.04$ ). This again suggests that postmessage engagement played an important role as a mediator.

In sum, the analyses show significant positive total and direct effects through two mediators (narrative transportation and post-message engagement) of external disadvantage on consumers' purchase intention, as the confidence intervals did not include zero. These findings support H2b. The path coefficients, direct (c'), and total effects (c) are displayed in Figure 3.

\section{Insert Figure 3 about here}

\section{Discussion}

\section{Theoretical implications}

Prior research (Paharia et al, 2011) indicates that brand biographies influence consumers' responses to brands. Underdog brand biographies that are characterized by high levels of passion/determination and external disadvantage (Paharia et al, 2011) are particularly successful in positively affecting consumers' brand preferences and purchase intentions (Paharia et al, 2011). Such positive effects arise especially when consumers identify themselves as underdogs or purchase products for their own usage as opposed to others' (Paharia et al, 2011). Moreover, the literature on narrative transportation suggests that narratives can change the attitudes, beliefs, and behaviors of the recipients of narrative information- - because persuasion occurs as consumers immerse themselves in the story (Escalas, 2004; Green and Brock, 2000; Green, 2004; Hormes et al, 2013). Narratives have also been associated with enhanced post-message engagement (Nabi and Green, 2015). The current research extended this literature in several 
ways: First, it investigated the individual impact of passion/determination and external disadvantage conveyed in brand biographies on consumer responses to the brand. In this research, passion/determination and external disadvantage emerged as independent aspects of brand biographies in that they were not significantly correlated. Passion/determination and external disadvantage also had differential effects on consumers' purchase intentions:

Passion/determination had a significant and positive direct effect on consumers' purchase intentions, whereas external disadvantage did not influence consumers' purchase intentions directly. These findings suggest that passion/determination conveyed in brand biographies have a relatively stronger direct effect on consumers' purchase intention than external disadvantage.

Second, this research added new insights regarding the processes underlying the effect of brand biographies on consumer responses to the brand. It examines the mediating role of narrative transportation and post-message engagement-including information seeking, postnarrative message elaboration, and social sharing - in the relation between passion/determination and external disadvantage. Both narrative transportation and consumers' post-message engagement mediated the effects of passion/determination as well as external disadvantage on consumers' purchase intentions. Moreover, post-message behaviors engagement emerged as the most important mediator in terms of the indirect effect for the influence of both passion/determination and external disadvantage on consumers' purchase intentions.

\section{Managerial implications}

Building on prior research, this research offers additional evidence that the use of brand biographies in brand communications entail positive outcomes, such as increased purchase intention. This evidence emerged in a new product category, using a regression approach to 
examine the independent roles of passion/determination, and involving a sample of adult consumers. Especially the notion of passion/determination reflected in a brand biography led to strong and positive direct and indirect effects on consumers' purchase intentions. Higher levels of external disadvantages described in a brand biography also had positive consequences, albeit only indirectly by enhancing consumers' narrative transportation into the biography and by strengthening their post-message engagement. Overall, the results of this research suggest that the use of brand biographies that evoke a high level of passion/determination and external disadvantage are a valuable tool in brand communications. The findings of this research underscore the importance of emphasizing how passionate and determined the brand and its founders were in overcoming external struggles to be successful. Nonetheless, the current research indicates that the level of external disadvantage conveyed in the brand biography does not directly affect consumer responses, but influences them through a persuasive process involving narrative transportation and post-message engagement. This suggests that brand biographies that make reference to external disadvantages the brand had to overcome are nonetheless beneficial. Overall, however, brand managers would benefit more from emphasizing passion and determination when writing their brand stories and in designing communication strategies. In other words, brand biographies should talk less about how externally disadvantaged the brand is, and refer to a greater extent to the brand's passion and determination with regard to succeeding in the industry.

Important from a managerial standpoint is also that biographies that involve high levels of passion/determination and external disadvantage stimulate post-message engagement in terms of information seeking about the brand, post-message elaboration, and social sharing. Postmessage engagement may thus not only positively influence purchase intentions, but lead to 
positive behavioral outcomes. These include finding out more about the brand and its attributes, social interactions that result in the diffusion of information about the brand. Such behavioral outcomes benefit the brand as well. Because post-message engagement emerged as an important mediator with regard to the effect of both passion/determination and external disadvantage, brand managers would do well in facilitating consumers' behavioral expression of post-message engagement. For example, to enhance information seeking behaviors, availability and accessibility of brand information to encourage online, on social media, or in-store browsing and comparison could be helpful. Providing information in a format that consumers can easily share via social media would also be beneficial to encourage post-message engagement behaviors. In addition, to enhance social sharing behaviors, brand manager could encourage consumers to share the brand narrative as well as brand experiences with other consumers. One of the strategies that organizations currently use consists contests in which consumers post and distribute their thoughts and stories about the brand on various social network platforms. Such activities have the potential to considerably increase the reach of a brand's communication strategy.

\section{Limitations and future research}

This research has several limitations that need to be acknowledged. First, according Green and Brock (2000, p. 719), "the most powerful tales tends to be those that involve negative aspects, such as dilemmas to be overcome." Underdog brand biographies meet this criterion because they elaborate on the external disadvantages that once faced the brand, and the passion and determination it took to overcome these odds. The current research thus focused on the influence of consumers' perceptions of the passion/determination and external disadvantage 
conveyed in a brand biography on narrative transportation, post-message engagement, and subsequent purchase intentions. In addition to passion/determination and external disadvantage — which are two content related characteristics of brand biographies — it is very likely that other factors, such as the narrative quality and the cultural appropriateness of the story impact the persuasive process. Future research could shed more light on how the elements within a brand biography should be conveyed. This may require research that is more qualitatively oriented and examines consumers' thought processes in responses to reading brand biographies.

Another possible concern regarding the current research is the measurement of consumers' perceptions of external disadvantage reflected in brand biographies. Although this research used a scale developed and used in prior research ("How externally disadvantaged is this brand?" anchored not at all/very much; Paharia et al, 2011), this question may be somewhat ambiguous to consumers. External disadvantage is a relatively abstract term that could make reference to challenges in the financial, human resources, experience, distribution, or market domain. It is possible that participants found it difficult to express their perceptions using this summary item, and this may have influenced the observed relation between external disadvantage and purchase intentions. Although it was preferable to use existing measures in the current research, future research directed at developing a measure that is more easily accessible to participants might be fruitful. Relatedly, the narrative transportation index used in this research was formed with nine of the twelve-item narrative transportation scale (Green and Brock, 2000), after removal of the three reversed scored items following a factor analysis. However, because the narrative transportation is an integrative melding of attention, imagery, and emotion (Green and Brock, 2000; Gerrig, 1993), individual measurement and consideration of the impact of these aspects of narrative transportation may provide a much more nuanced 
understanding with regard to the extent to which consumers experience focus, imagery, affect, and cognitive involvement within the transportation process. Such an investigation would help clarify which components of narrative transportation have the strongest effect on narrative persuasion.

Finally, this research used a specific type of narrative — namely a short text — to examine the effect of passion/determination and external disadvantage on consumers' purchase intentions. In the marketing literature on brand biographies, such an approach is common (e.g., Paharia et $a l, 2011)$. It also reflects the managerial practice of presenting written brand biographies on company websites. Narrative transportation is not limited to reading written text, however. The narrative transportation literature documents the effect of a variety of narratives, such as written stories (Green and Brock, 2000; Green, 2004; Mazzocco et al, 2010), print advertisements (Escalas, 2004), films (Green et al, 2008), short clips (Sestir and Green, 2010), and web reviews (Hamby et al, 2015). Because brands rely on a consistent delivery of communication across multiple touchpoints, a consideration of non-textual brand narratives could provide important insights - both in terms of the degree of narrative transportation that is evoked and its effect on persuasion and consumer responses to brands. It is likely that the results would be consistent with the current research, as narrative transportation processes appear to occur regardless of the type of narrative (Green and Brock, 2000). It is possible that image or video-based narrative forms enhance narrative transportation compared to text-based forms. This could potentially strengthen the downstream effects.

Overall, the current research provides strong evidence for a positive effect of brand biographies on consumer responses, shed light on the process involving narrative transportation, integrated post-message engagement as a new, theoretically and managerially significant 
mediator into this model, and identified additional avenues for future research on brand biographies. 


\section{Conflict of Interest Statement}

On behalf of all authors, the corresponding author states that there is no conflict of interest. 


\section{References}

Adaval, R. and Wyer, R.S. (1998) The role of narratives in information processing. Journal of Consumer Research, 7(3): 207-245.

Avery, J., Paharia, N., Keinan, A. and Schor, J.B. (2010) The strategic use of brand biographies. In: R.W. Belk (ed.) Research in Consumer Behavior (Volume 12) pp. 213-229.

Cooper, H., Schembri, S. and Miller, D. (2010) Brand-self identity narratives in the James Bond movies. Psychology and Marketing, 27(6): 557-567.

Dal Cin, S., Zanna, M.P. and Fong, G.T. (2004) Narrative persuasion and overcoming resistance. In E.S. Knowles and J.A. Linn (eds.) Resistance and Persuasion. Mahwah, NJ: Lawrence Erlbaum, pp. 175-191.

Escalas, J.E. (2004) Narrative processing: Building consumer connections to brands. Journal of Consumer Psychology, 14(1): 168-179.

Escalas, J.E. (2007) Self-referencing and persuasion: Narrative transportation versus analytic elaboration. Journal of Consumer Research, 33(1): 412-429.

Escalas, J.E. and Bettman, J. (2005) Self-construal, reference groups, and brand meaning. Journal of Consumer Research, 32(4): 378-389.

Green, M.C. (1996) Mechanisms of narrative-based belief change. MA thesis, Ohio State University, Columbus, Ohio.

Green, M.C. (2004) Transportation into narrative worlds: The role of prior knowledge and perceived realism. Discourse Processes, 38(2): 247-266.

Green, M.C. and Brock, T.C. (2000) The role of transportation in the persuasiveness of public narratives. Journal of Personality and Social Psychology, 79(5): 701-721.

Green, M.C., Brock, T.C. and Kaufman, G.F. (2004) Understanding media enjoyment: The role 
of transportation into narrative worlds. Communication Theory, 14(4): 311-327.

Green, M.C., Kass, S., Carrey, J., Herzig, B., Feeney, R. and Sabini, J. (2008) Transportation across media: Repeated exposure to print and film. Media Psychology, 11(4): 512-539.

Hamby, A., Daniloski, K. and Brinberg, D. (2015) How consumer reviews persuade through narratives. Journal of Business Research, 68(6): 1242-1250.

Hatch, M.J. and Rubin, J. (2006) The hermeneutics of branding. Journal of Brand Management, 14(1): 40-59.

Hayes, A.F. (2012) PROCESS: A versatile computational tool for observed variable mediation, moderation, and conditional process modeling [White paper]. Retrieved from http://www.afhayes.com/public/process2012.pdf

Hormes, J.M., Rozin, P., Green, M.C. and Fincer, K. (2013) Reading a book can change your mind, but only some changes last for a year: food attitude changes in readers of The Omnivore's Dilemma. Frontiers in Psychology, 4(778): 1-8.

Keinan, A., Paharia, N. and Avery, J. (2010) Capitalizing on the underdog effect. Harvard Business Review, 88(11): 32.

Kao, D.T. (2015) Is Cinderella resurging? The impact of consumers' underdog disposition on brand preferences: Underdog brand biography and brand status as moderators. Journal of Consumer Behavior, 14(5): 307-316.

Mazzocco, P.J., Green, M.C., Sasota, J.A. and Jones, N.W. (2010) This story is not for everyone: Transportability and narrative persuasion. In M.C. Green, J.J. Strange, and T.C. Brock (eds.) Narrative Impact: Social and Cognitive Foundations. Mahwah, NJ: Lawrence Erlbaum, pp. 157-181.

Merchant, A. and Rose, G.M. (2013) Effects of advertising-evoked vicarious nostalgia on brand 
heritage. Journal of Business Research, 66(12): 2619-2625.

Nabi, R.L. and Green, M.C. (2015) The role of a narrative's emotional flow in promoting persuasive outcomes. Media Psychology, 18(2): 137-162.

Oatley, K. (1999) Why fiction may be twice as true as fact: Fiction as cognitive and emotional simulation. Review of General Psychology, 3(2): 101-117.

Paharia, N., Keinan, A., Avery, J. and Schor, J.B. (2011) The underdog effect: The marketing of disadvantage and determination through brand biography. Journal of Consumer Research, 37(5): 775-790.

Paharia, N., Avery, J. and Keinan, A. (2014) Positioning brands against large competitors to increase sales. Journal of Marketing Research, 51(6): 647-656.

Pecot, F., Merchant, A., Valette-Florence, P. and De Barnier, V. (2018) Cognitive outcomes of brand heritage: A signaling perspective. Journal of Business Research, 85(3): 304-316.

Petty, R.E. and Cacioppo, J.T. (1986) The elaboration likelihood model of persuasion. Advances in Experimental Social Psychology, 19(1): 123-205.

Priester, J.R., Nayakankuppam, D., Fleming, M.A. and Godek, J. (2004) The A2SC2 model: The influence of attitudes and attitude strength on consideration and choice. Journal of Consumer Research, 30(4): 574-587.

Rimé, B. (1995) The social sharing of emotion as a source for the social knowledge of emotion. In J.A. Russell, J.M. Fernandez-Dols, A.S.R. Manstead and J.C. Wellenkamp (eds.) Everyday Conceptions of Emotion: An Introduction to the Psychology, Anthropology, and Linguistics of Emotion. Kluwer: Doordrecht, Netherlands, pp. 475-489.

Rose, G.M., Merchant, A., Orth, U.R. and Horstmann, F. (2016) Emphasizing brand heritage: Does it work? And how? Journal of Business Research, 69(2): 946-963. 
Sestir, M. and Green, M.C. (2010) You are who you watch: Identification and transportation effects on temporary self-concept. Social Influence, 5(4): 272-288.

Schembri, S., Merrilees, B. and Kristiansen, S. (2010) Brand consumption and narrative of the self. Psychology \& Marketing, 27(6): 623-638.

Simonin, B.L. and Ruth, J.A. (1998) Is a company known by the company it keeps? Assessing the spillover effects of brand alliances on consumer brand attitudes. Journal of Marketing Research, 35(1): 30-42.

Slater, and Rouner (2002) Entertainment-education and elaboration likelihood: Understanding the processing of narrative persuasion. Communication Theory, 12(2): 173-191.

Sprott, D.E. and Shimp, T.A. (2004) Using product sampling to augment the perceived quality of store brands. Journal of Retailing, 80(4): 305-315.

Twitchell, J.B. (2004) An English teacher looks at branding. Journal of Consumer Research, 31(3): 484-489.

Urde, M, Greyser, S.A. and Balmer, J.M.T. (2007) Corporate brands with a heritage. Journal of Brand Management, 15(1): 4-19.

Van Laer, T., de Ruyter, K., Visconti, L.M. and Wetzels, M. (2014) The extended transportationimagery model: A meta-analysis of the antecedents and consequences of consumers' narrative transportation. Journal of Consumer Research, 40(5): 797-817.

Wallendorf, M. and Arnould, E.J. (1988) "My favorite things": A cross-cultural inquiry into object attachment, possessiveness, and social linkage. Journal of Consumer Research, 14(4): $531-547$.

Wheeler, S.C., Petty, R.E. and Bizer, G.Y. (2005) Self-schema matching and attitude change: Situational and dispositional determinants of message elaboration. Journal of Consumer 
Research, 31(4): 787-797.

Wiedmann, K.-P., Hennings, N., Schmidt, S. and Wuestefeld, T. (2011) Drivers and outcomes of brand heritage: Consumers' perception of heritage brands in the automotive industry. Journal of Marketing Theory and Practice, 19(2): 205-220.

Woodside, A.G., Sood, S. and Miller, K.E. (2008) When consumers and brands talk: Storytelling theory and research in psychology and marketing. Psychology and Marketing, 25(2): $97-$ 145.

Woodside, A.G. (2010) Brand-consumer storytelling research: Introduction to a Psychology \& Marketing special issue. Psychology and Marketing, 27(6): 531-540.

www.google.com/about/our-story, accessed March 20, 2018. 


\section{Figure 1}

\section{Conceptual model}

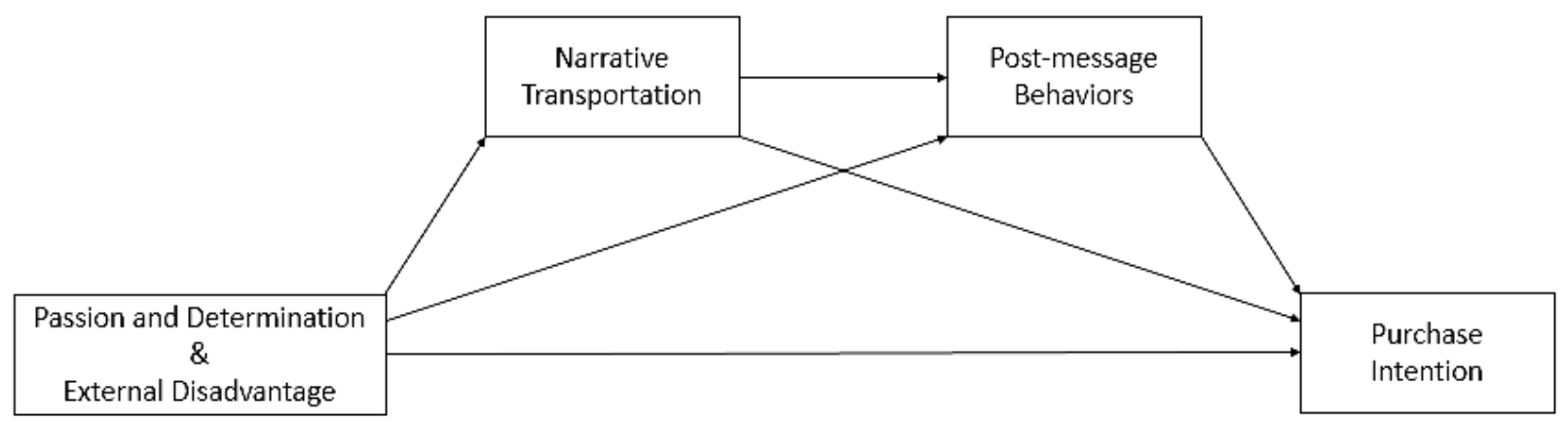




\section{Figure 2}

PROCESS model results for the effects of passion/determination

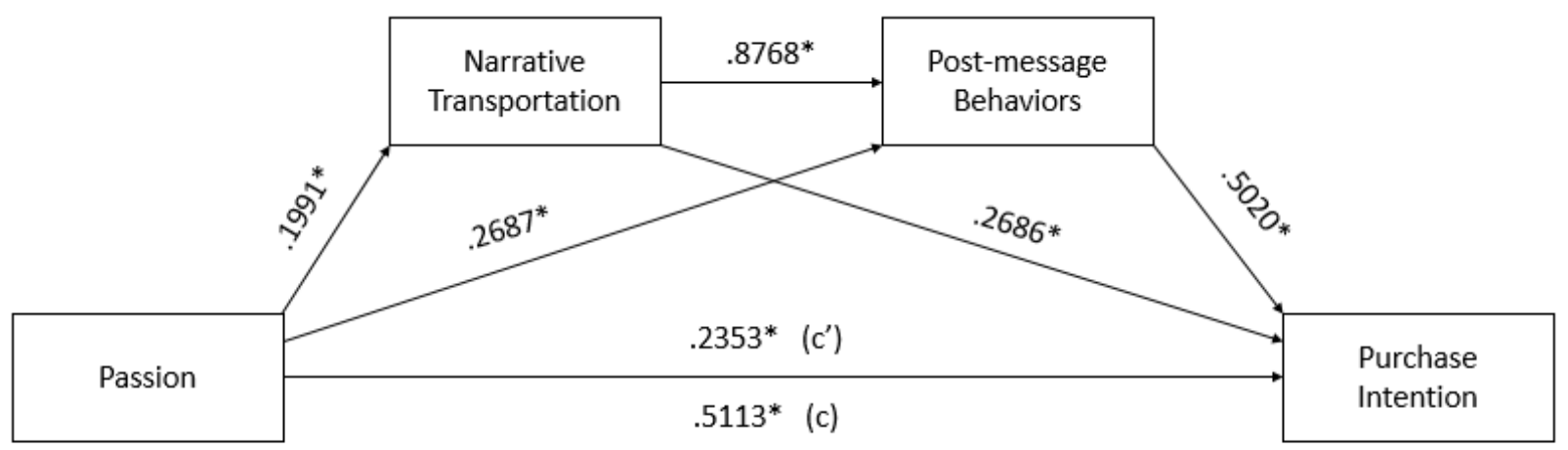

${ }^{*}$ Indicates significance at the $p<.001$ level 


\section{Figure 3}

PROCESS model results for the effects of external disadvantage

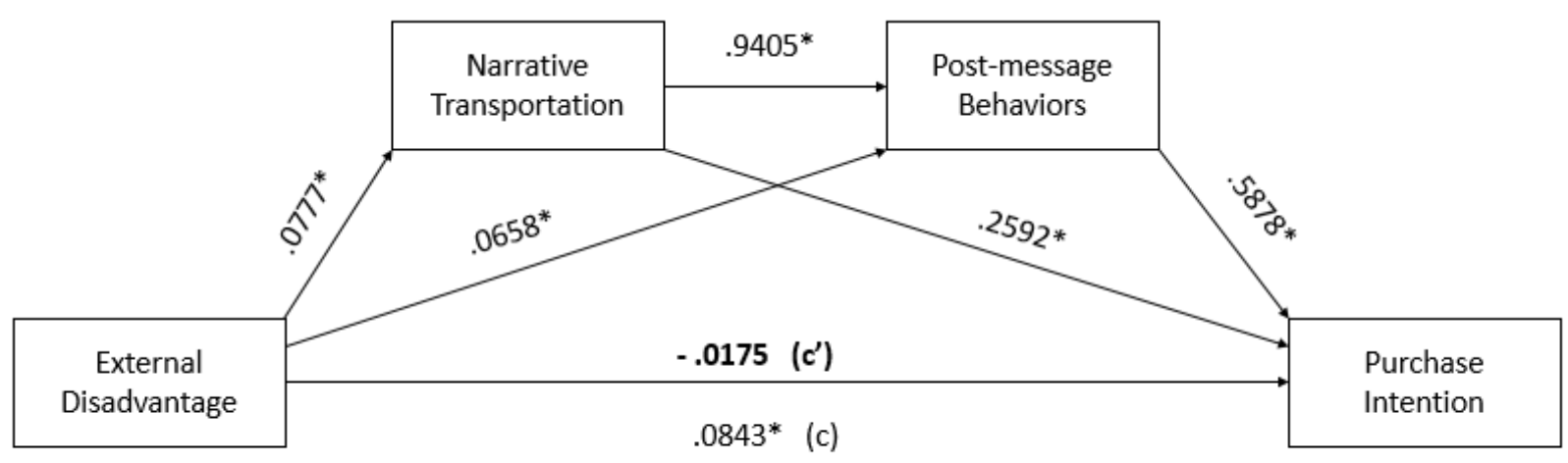

*Indicates significance at the $p<.001$ level 


\section{Appendix A - Brand Biographies}

\section{Low passion/determination and external disadvantage}

Juicy Juice is a premium fresh bottled juice maker that has done well in the juice market for years. This large company has more resources than the industry average due to pioneering technologies and strong partnerships with established groves, distributors, and retailers. The brand's founders have significant experience in beverages industry and are known to maintain high quality in the production process.

Juicy Juice is part of an international food corporation that was able to build the brand with a large marketing and distribution budget without compromising premium quality. Known for its dominant market position and financial performance, Juicy Juice is regarded to be a highquality premium fresh juice available at most beverage and grocery stores.

\section{High passion/determination and external disadvantage}

Juicy Juice is a local fresh bottled juice maker that has entered the market only last year. This small company has less resources than the industry average due to limited manufacturing capacity and developing partnerships with groves, distributors, and retailers. Although the brand's founders do not have much experience in beverages industry, they strongly believe that their dedication and passion for a healthy lifestyle and fresh juice will help them overcome the odds of competing in a fierce industry to bring their high-quality juices to market.

Juicy Juice is a brand that faces a huge challenge of dealing with a limited marketing and distribution budget without comprising premium quality. Though still relatively less known compared to powerful competitors, Juicy Juice is regarded to be a high-quality premium fresh juice available at some beverage and grocery stores. 